\title{
Evaluation of Trichoderma harzianum as a potential bio- control option for fungal root disease of Seabuckthorn
}

Nivedita Malik* and B.S. Bhandari

Department of Botany \& Microbiology, H.N.B Garhwal University, Srinagar (Garhwal), India.

Received: 15-04-2018; Revised: 20-05-2018; Accepted: 17-06-2018

\begin{abstract}
Biocontrol involves harnessing disease suppressive micro-organisms to improve plant health. Owing to the shortage of available fungicides for economic management of soil borne diseases, alternative techniques such as biological control are increasingly being sought for disease management. The present work was carried out to study the potential of Trichoderma harzianum isolate screened from the rhizospheric soil of seabuckthorn growing areas in Uttarakhand. Antagonistic activity of isolate was observed against Fusarium oxysporum causing damping off disease in seabuckthorn. Under in vitro conditions Trichoderma harzianum significantly reduced the growth of pathogenic Fusarium oxysporum.
\end{abstract}

Keywords: Antagonistic, disease, Fusarium, isolate, rhizosphere, soil

\section{Introduction}

The northern part of India harbours a great diversity of medicinal plants because of the majestic Himalayan range. So far about 8000 species of angiosperms, 44 species of gymnosperms and 600 species of pteridophytes have been reported in the Indian Himalaya, of these 1748 species are known as medicinal plants (Kala and Mathur, 2002). The World Health Organization (WHO) estimated that $80 \%$ of the population of developing countries relies on traditional medicines, mostly plant drugs, for their primary health care needs (Sekar and Kandavel, 2010). Seabuckthorn is one of the main plants collected and exploited unscientifically from Uttarakhand due to its use as food, medicines and cosmetics. It is also known as "wonder plant" due to its multifarious benefits.

Seabuckthorn is also affected by many soil borne pathogenic fungi which effects its production and yield. Soil borne pathogenic fungi are responsible for numerous economically important root diseases. Root rot diseases are more difficult to manage than many foliar diseases because they often are not detected before substantial damage has already occurred (Harveson \& Rush, 2002; Harveson et al., 2002a). Phytopathogenic microorganisms have a great impact on crop yields and can significantly reduce plant performance and crop quality. They are serious threat to crop production and ecosystem stability. Different methods have been used to control plant pathogens, being the most used cultural practices, resistant cultivars, chemical and biological control. A major factor influencing plant growth and health is the microbial population living both in the rhizosphere and as endophytes within healthy plant tissue. Even though, some success has *Corresponding Author:

Nivedita Sharma,

Department of Botany \& Microbiology,

H.N.B Garhwal University, Srinagar (Garhwal), Uttarakhand

Country India.

E-mail: maliknivedita8730@gmail.com been achieved in controlling crop pathogens using bio-control options. Biological control agents support plant health via the suppression of plant pathogens (Dalal and Kulkarni, 2013). Biological control is a natural and specific way to control pathogens and enhance crop yield by growth promoting attribute of environment friendly microorganisms.

The present study aims to evaluate the role of rhizosphere associated fungus Trichoderma harzianum as a biocontrol option for fungal root disease i.e. damping off in seabuckthorn. There is an urgent need to develop effective and more consistent biocontrol agents in order to increase survival and growth of medicinal plants under field conditions. Though much information is available on activity of soil micro organisms and plant growth promotion for annual crops, very limited information is available in respect of biocontrol agents associated with rhizosphere of medicinal plants such as seabuckthorn.

\section{Materials and Methods}

Isolation and Identification of pathogen

Diseased samples were collected from different locations of Chamoli district in Uttarakhand. Diseased roots of Hippophae salicifolia were taken into the laboratory and washed thoroughly with running tap water to remove the surface dirt. The roots were cut into small pieces using sterile scalpel blades and kept in sterile petri dishes after surface sterilizing with 0.1 percent mercuric chloride for about one minute followed by two changes of sterile water. Further isolation of the fungus was done by performing moist chamber incubation 
method (Shutleff and Averre, 1997). These surface sterilized pieces were then placed between blotting papers and aseptically inoculated onto petridishes containing Potato Dextrose Agar media. The plates were incubated at $25 \pm 2^{\circ} \mathrm{C}$ for 5 to 6 days, and the growth of fungal colonies were recorded every day. Fungal colonies were isolated after 5-6 days and pure cultures were transferred to Potato Dextrose Agar slant. The mycelia and spore characters of the fungi were studied under microscope. Fungal isolates were identified on the basis of cultural, morphological and microscopic characteristics viz. Mycelium, sporangiophore, spore bearing organ, spore structure etc. and were identified following Barnett and Hunter (1972) and Gilmann (1967). Pure culture of Fusarium oxysporum was stored at $5^{\circ} \mathrm{C}$ in culture tubes and petri plates containing PDA.

Isolation of rhizosphere associated fungal isolate:

Rhizosphere soil samples of seabuckthorn were collected from some selected sites of district Chamoli in Uttarakhand. Soil samples were collected in sterile polythene bags. The isolation of rhizosphere fungi from these was done by dilution plate method of Wakesman (1927) and Warcup (1950). This method includes shaking of $1 \mathrm{~g}$ soil in $100 \mathrm{ml}$ of distilled water followed by further dilutions under asceptic conditions. Various dilutions were cultured on Potato Dextrose Agar medium and Czapek's Dox medium (Raper and Thom, 1949). The colonies with characteristic growth of Trichoderma spp were observed under the microscope and growth from such colonies was sub cultured on agar slants and the fungi were identified following Barnett and Hunter (1972) and Gilmann (1967).
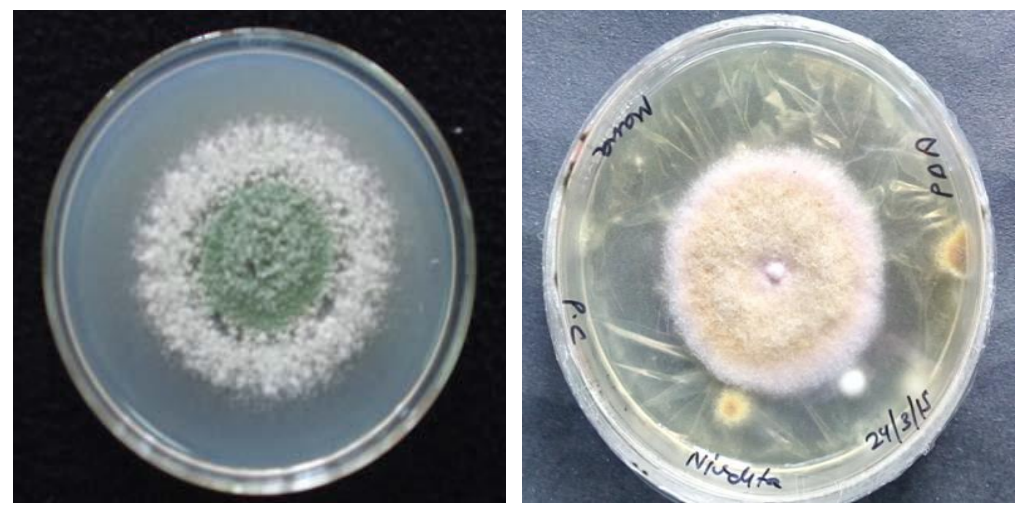

Plate 1. Colony and microscopic morphology of T.harzianum

Plate 2. Colony and microscopic morphology of F.oxysporum

\section{In vitro dual culture assay:}

Dual culture method (Rao, 2003) was employed to evaluate the antagonistic activity of $T$. harzianum. Four mm diameter mycelial disc from the periphery of 10 day old culture of bioagent was placed on the petri plate at four locations, approximately $3 \mathrm{~cm}$ from the center. A loopful of actively growing Fusarium oxysporum isolate (Plate 2) was placed opposite to T.hariianum isolate on the plate. Plates inoculated with Fusarium oxysporum but not with $T$. harzianum were used as control. All in vitro tests of antagonism were performed three times. All plates were incubated at $27^{0} \mathrm{C}$ for 7 days. Visual observations of growth inhibition were recorded every two days and the final measurements were recorded at the $7^{\text {th }}$ day for incubation. Degree of antagonism was determined by measuring the radial growth of pathogen, (radial mycelia growth reduction) Fusarium oxysporum by Trichoderma harzianum in dual culture in relation to growth of the control. Three replications were maintained for each treatment. Percentage inhibition of pathogen was calculated by the following formula (Fokkema, 1973). R1-R2/R1x100, where R2 denotes the radial growth of the pathogen towards the opponent antagonist and R1 denotes the radial growth of the pathogen towards opposite side.

\section{Results and Discussion}

\section{Isolation of Trichoderma harzianum}

A number of colonies were observed in PDA plate after 3-7 days when serially diluted samples were placed on PDA media. Colony that produced green colour conidia was picked, observed under microscope by staining with lactophenol cotton blue stain. The microscopic analysis of the mycelium with spore revealed that the isolate was Trichoderma harzianum (Plate 1). The isolate was sub cultured and stored in PDA slants at $-20^{\circ} \mathrm{C}$. 


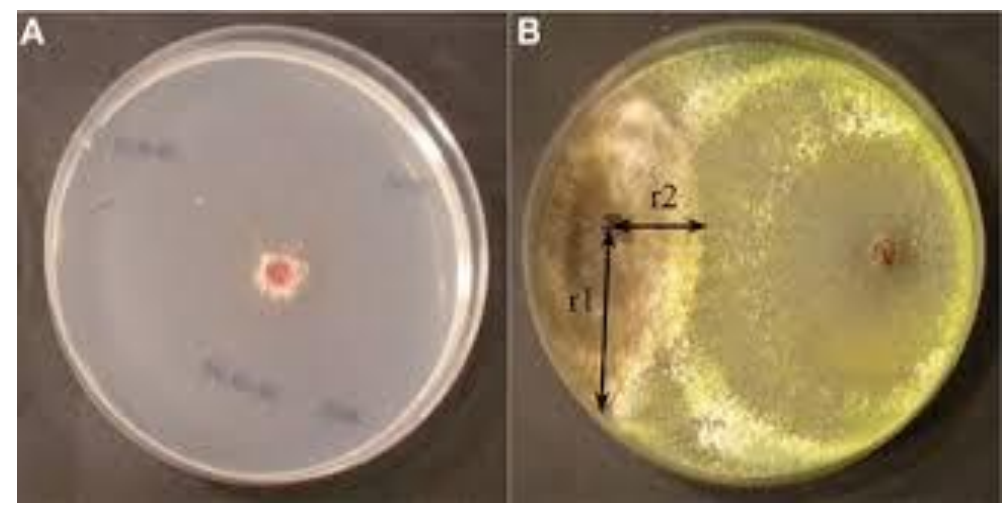

Plate 3. Antagonistic potential of T. harzianum against Fusarium oxysporum a) Control b) Dual Culture

Trichoderma harizanum was evaluated for its antagonistic activity against Fusarium oxysporum in Petri dishes containing PDA medium. Results showed that $T$. harizanum inhibited the growth of pathogen. Growth inhibition in the pathogen differed significantly. Seven days of incubation showed different degrees of mycelia growth inhibition of F.oxysporum (Plate 3). Initially very less inhibition was observed near the intermingled contact zone of F.oxysporum and T.harianum. However, after 4 days of incubation there was suppression of growth on antagonized portion of hyphae. T.harzianum completely overgrew the pathogen with percentage inhibition of $70 \%$.

The geunus, Trichoderma is ubiquitous which has been extensively studied for their biological control of plant diseases. Strains of Trichoderma are strong opportunistic invaders fast growing, prolific producers of spores and powerful antibiotic producers. The antagonistic activity of Trichoderma species depends on multiple synergistic mechanisms. According to Papavizas and Lumsden (1982); Devaki et al., (1992), the mechanisms involved in the control of pathogens by Trichoderma spp. are probably due to antibiosis, lysis, competition and mycoparasitism. The species of Trichoderma have shown efficiency in the biological control of many foliar diseases. The Trichoderma may suppress the growth of the pathogen population in the rhizosphere through competition and thus reduce disease development. It produces antibiotics and toxins such as trichothecin and a sesquiterpine, Trichodermin, which have a direct effect on other organisms. The antagonist (Trichoderma) hyphae either grow along the host hyphae or coil around it and secrete different lytic enzymes such as chitinase, glucanase and pectinase that are involved in the process of mycoparasitism.

\section{Conclusion}

Treatment of valuable plant wealth is possible through the use of various pesticides, insecticides and other chemicals. The intensive use of fungicides for the control of diseases has resulted in the accumulation of toxic chemicals which are hazardous to human beings and to the environment. Chemical treatments are not ecofriendly and, therefore, effective bio-control mechanisms have some hope to treat such plants in a healthy vision. The residual chemical pesticides on various parts also seriously affect the marketing 9potential of medicinal plants and their formulations. The increasing awareness of fungicide related hazards has emphasized the need for adopting a safer biological method but unfortunately very little work has been done to search for microbial antagonists which could serve as biocontrol agents against Hippophae salicifolia diseases. For this purpose Trichoderma harzianum was screened out for its antagonistic activity against Fusarium oxysporum. Fortunately, it proved to be a success acting as strong antagonist against the pathogen.

\section{References}

1. Barnett, H.L, and B.B Hunter. "Illustrated Genera of Imperfect Fungi". Burges Publishing Company, Minnesota.

2. Dalal, J, and N Kulkarni. "Antagonistic and plant growth promoting potential of indigenous endophytic bacteria of soyabean (Glycine max (L.), Merril)". Current Research in Microbiology and Biotechnology, 1.2 (2013): 6-69.

3. Devaki, N.S, S.S Bhat, and K.R Manjunath. "Antagonistic activities of Trichoderma harzianum against Pythium aphanidermatum and Pythium myriotylum on tobacco". Journal of Phytopathology 136 (1992): 8287.

4. Fokkema, N.J, "The role of saprophytic fungi in antagonism against Derchslera sorokaniana (Helminthosporium sativum) on agar plates and on rye leaves with pollen". Physiological Plant Pathology 3 (1973):195-205.

5. Gilman, J.C. A Manual of Soil Fungi. 2 Indian ed., Biotech Books, Delhi, (2001) p.392.

6. Harveson, R.M, and C.M Rush. "The influence of irrigation frequency and cultivar blends on the severity of multiple root diseases in sugar beets". Plant Disease, 86 (2002): 901-908 
7. Harveson, R.M., G.L Hein; J.A Smith.; R.G Wilson; C.D Yonts. "An integrated approach to cultivar evaluation and selection for improving sugar beet profitability: a successful case study for the Central High Plains". Plant Disease, 86 (2002a): 192-204

8. Kala, C.P, and V.B Mathur. "Patterns of plant species distribution in the trans-Himalayan region of Ladakh, India." Journal of Vegetation Science 13 (2002):751-754

9. Papavizas, G.C. and R.D Lumsden. "Improved medium for isolation of Trichoderma spp. from natural soil". Plant Disease, 66 (1982): 1019 - 1020.

10. Rao, N. S. S. Methods used in soil Microbiological studies. Soil Microbiology. 4th Edition (2003) pp: 6172. (Oxford and IBH Publishing Co.Pvt.Ltd. New Delhi).

11. Raper, K.B. and C. Thom. A manual of the Penicillia. Williams and Wilkins Co., Baltimore. (1949) pp.875.
12. Sekar, S. and D. Kandavel. "Interaction of plant growth promoting rhizobacteria (pgpr) and endophytes with medicinal plants - new avenues for phytochemicals." J. Phytology. 2 (2010): 91-100.

13. Shutleff, M.C and C.W Averre. "The Plant Disease Clinic and field diagnosis of abiotic diseases". Am. Phytopathol. Soc. (1997) St.Paul, MN

14. Warcup, J.H. Isolation of fungi from hyphae present in soil. Nature, Lond. 175(1955a): 953.

15. Webber, J.F. and J.N Hedger. "Comparison of interactions between Ceratocystis ulmi and Elm bark saprobes in vitro and in vivo". Transactions of British Mycological Society 86 (1986): 93-01.

\section{Cite this article as:}

Nivedita Malik and B.S. Bhandari. Evaluation of Trichoderma harzianum as a potential bio-control option for fungal root disease of seabuckthorn. Annals of Plant Sciences 7.7 (2018) pp. 2373-2376.

do http://dx.doi.org/10.21746/aps.2018.7.7.1

Source of support: Nil.

Conflict of interest: Nil. 